Int. J. Electrochem. Sci., 14 (2019) $8311-8325$

International Journal of

ELECTROCHEMICAL

SCIENCE

www.electrochemsci.org

\title{
A Mexacarbate Electrochemical Biosensor on Carbon Materials Based on a Functionalized Multiwalled Carbon Nanotube Modified Glassy Carbon Electrode
}

\author{
J. Tharini ${ }^{1, *}$, Tse-Wei Chen ${ }^{2,3}$, Shen-Ming Chen $^{2, *}$, R. Saraswathi ${ }^{4}$, \\ Mohamed S. Elshikh ${ }^{5}$, Noura M.Darwish ${ }^{6}$, Syang-Peng Rwei ${ }^{3,7}$ \\ ${ }^{1}$ Sethu Institute of Technology, Pulloor-626115, Kariapatti, TN, India \\ ${ }^{2}$ Department of Chemical Engineering and Biotechnology, National Taipei University of Technology, \\ Taipei 106, Taiwan. \\ ${ }^{3}$ Research and Development Center for Smart Textile Technology, National Taipei University of \\ Technology, Taipei 106, Taiwan, ROC \\ ${ }^{4}$ Department of Materials Science, School of Chemistry, Madurai Kamaraj University, Madurai - 625 \\ 021, Tamilnadu, India \\ ${ }^{5}$ Department of Botany and Microbiology, College of Science, King Saud University, P.O. Box 2455 \\ Riyadh 11451, Saudi Arabia. \\ ${ }^{6}$ Biochemistry Department, Ain Shams University, Cairo, Egypt. \\ ${ }^{7}$ Institute of Organic and Polymeric Materials, National Taipei University of Technology, Taipei 106, \\ Taiwan, ROC \\ *E-mail: smchen78@ms15.hinet.net (Shen-Ming Chen), tharinichem@gmail.com (J.Tharini)
}

doi: $10.20964 / 2019.08 .103$

Received: 15 April 2019 / Accepted: 18 June 2019 / Published: 30 June 2019

The commercial multi-walled carbon nanotube (MWCNT) was carboxylated using sulphuric and nitric acid and characterized by various techniques such as scanning eletron spectroscopy, Infra-red spectroscopy and atomic force microscopy. The acid functionalized multiwalled carbon nanotube serves as the effective matrix for the sensing of carbamate pesticide namely mexacarbate. The electrochemical oxidation of mexacarbate at GCE and MWCNT/GCE follows heterogeneous electron transfer reaction. Different experimental parameters such as the effect of scan rate and $\mathrm{pH}$ were studied. Rotating disk electrode voltammetry studies confirms the one-electron transfer reaction. The sensor calibration plot for mexacarbamate was constructed by means of pulse technique. The acid functionalized multiwalled carbon nanotube sensor was applied to real water sample with the recovery percentage of $85-89 \%$.

Keywords: Mexacarbate, differential pulse voltammetry, multi-walled carbon nanotube, glassy carbon electrode, calibration plot

$\underline{\text { FULL TEXT }}$ 
(C) 2019 The Authors. Published by ESG (www.electrochemsci.org). This article is an open access article distributed under the terms and conditions of the Creative Commons Attribution license (http://creativecommons.org/licenses/by/4.0/). 